\title{
PIJAT BAYI TERHADAP PENINGKATAN FREKUENSI DAN DURASI MENYUSU PADA BAYI
}

\section{BABY MASSAGE ON IMPROVEMENT FREQUENCY AND DURATION OF BREASTFEEDING A BABY}

\author{
Happy Marthalena Simanungkalit \\ Poltekkes Kemenkes Palangka Raya, Indonesia. \\ E-mail: happy4lena@gmail.com
}

\begin{abstract}
ABSTRAK
Pemberian pijat bayi, akan memberikan stimulasi pada kulitnya sehingga terjadi potensial aksi pada sistem saraf, yaitu saraf simpatis dan saraf parasimpatis. Penelitian ini bertujuan untuk mengetahui pengaruh pijat bayi terhadap peningkatan frekuensi dan durasi menyusu pada bayi. Penelitian ini merupakan penelitian analitik dengan jenis penelitian yang digunakan yaitu Quasi Experiment. Populasi dalam penelitian ini adalah semua bayi usia 1-6 bulan di PMB "E" Kota Palangka Raya yang memenuhi kriteria inklusi dan eksklusi. Uji statistik yang digunakan yaitu Uji Manova. Hasil penelitian rata-rata frekuensi menyusu pada bayi sebelum dipijat adalah 7.3 kali per hari dan ratarata frekuensi menyusu setelah dipijat adalah 11.6 menit. Sedangkan, rata-rata durasi menyusu pada bayi sebelum dipijat adalah 21.50 menit per hari dan rata-rata durasi menyusu setelah dipijat adalah 39.00 menit. Hasil uji statistik frekuensi menyusu menunjukkan nilai $p=0,000$ karena $<0,05$ maka $\mathrm{H} 0$ ditolak. Hasil uji statistik durasi menyusu diperoleh nilai $p=0.002$, karena hasil uji yang diperoleh $<0.05$ maka $\mathrm{HO}$ ditolak. Hasil uji multivariat ada pengaruh yang signifikan dari variabel independen pada semua variabel dependen, nilai $p$-value menunjukkan $<0,05$. Ada pengaruh pijat bayi terhadap peningkatan frekuensi dan durasi menyusu pada bayi usia 1-6 bulan di PMB E. Saran bagi petugas kesehatan agar menjadikan terapi pijat bayi sebagai terapi alternatif dalam mendukung ASI eksklusif. Bagi masyarakat khususnya ibu menyusui agar rutin untuk melakukan pijat bayi minimal 2 kali seminggu agar kebutuhan nutrisi bayi terpenuhi karena durasi dan frekuensi menyusu meningkat. Bagi peneliti selanjutnya agar mengembangkan penelitian dengan menggunakan variabel produksi ASI yang belum diteliti terkait dengan pijat bayi dan menyusui.
\end{abstract}

Kata Kunci: Pijat bayi, frekuensi menyusu, durasi menyusu.

\begin{abstract}
Giving a baby massage will stimulate the skin so that action potentials occur in the nervous system, namely the sympathetic nerves and the parasympathetic nerves. This study aims to determine the effect of infant massage on increasing the frequency and duration of breastfeeding in infants. This study is an analytical study with Quasi-Experiment. The population in this study were all infants aged 1-6 months in PMB "E" that met the inclusion and exclusion criteria. The statistical test used is the Manova Test. The results of the average suckling frequency in infants before the massage were 7.3 times per day and the average frequency of breastfeeding after the message was 11.6 minutes. Meanwhile, the average duration of breastfeeding in infants before the message is 21.50 minutes per day and the average duration of breastfeeding after the message is 39.00 minutes. Statistical results of suckling frequency showed a value of $\mathrm{p}=0,000$ because $<0.05$ then $\mathrm{H} 0$ was rejected. The results of statistical tests of breastfeeding duration were obtained $p=0.002$ because the test results obtained were $<0.05$, then $\mathrm{H} 0$ was rejected. There is effect infant massage on increasing frequency and duration of breastfeeding in infants aged 1-6 months in PMB E. Advice for health workers make infant massage therapy an alternative therapy in supporting exclusive breastfeeding. Routinely baby massage at least 2 times a week so that the baby needs are met because of the duration and frequency of breastfeeding increases.
\end{abstract}

Keywords: Baby massage, breastfeeding frequency, duration of breastfeeding 


\section{PENDAHULUAN}

Cakupan pemberian ASI Ekslusif pada bayi di Kota Palangka Raya mencapai $14,99 \%$ lebih rendah bila dibandingkan dengan tahun sebelumnya dan target pemerintah untuk capaian pemberian ASI eksklusif adalah $80 \%$.

Pijat bayi menyebabkan bayi menjadi lebih rileks dan dapat beristirahat dengan efektif sehingga ketika bayi terbangun akan membawa energi cukup untuk beraktivitas. Bayi menjadi cepat lapar saat beraktifitas dengan optimal, sehingga nafsu makannya meningkat. Peningkatan nafsu makan ini juga ditambah dengan peningkatan aktivitas nervus vagus (sistem sarat otak yang bekerja untuk daerah leher ke bawah sampai dada dan rongga perut) dalam menggerakkan sel peristaltik untuk mendorong makanan ke saluran pencernaan, sehingga bayi lebih cepat lapar atau ingin makan karena pencernaannya semakin lancar. Penelitian Falikhah dan Hidayat menyatakan bahwa terdapat pengaruh pijat bayi terhadap frekuensi menyusui bayi usia 0-3 bulan. ${ }^{2}$

Penelitian ini dilakukan di Praktik Mandiri Bidan milik bidan "E" yang merupakan salah satu Praktik Mandiri Bidan di Kota Palangka Raya dengan fasilitas pijat dan spa bayi dan balita dengan kunjungan yang banyak. Rata-rata kunjungan 60-70 orang setiap bulannya. Penelitian dilakukan di PMB karena jumlah sampel yang banyak dan waktu penelitian yang singkat, maka responden yang datang ke PMB sesuai jadwal pijat bayi. Berdasarkan latar belakang di atas peneliti ingin melakukan penelitian untuk mengetahui pengaruh pijat bayi terhadap peningkatan frekuensi dan durasi menyusu bayi di PMB E.

Berdasarkan latar belakang tersebut, maka rumusan masalah dalam penelitian ini adalah "Bagaimana pengaruh pijat bayi terhadap peningkatan frekuensi dan durasi menyusu bayi? Pijat merupakan salah satu bentuk dari terapi sentuh yang berfungsi sebagai salah satu teknik pengobatan penting. Pijat bayi adalah seni tradisional yang menggabungkan sentuhan pengasuhan pada bayi yang dilakukan oleh orang tua, pengasuh atau terapis meliputi gerakan-gerakan dan teknik pijat. ${ }^{3}$ ASI
Eksklusif adalah bayi hanya diberi ASI saja selama 6 bulan, tanpa tambahan cairan lain. Menurut penelitian Purwani \& Darti (2012) bahwa sebagian besar bayi mendapat frekuensi menyusui dalam kategori baik $(75,0 \%)$ dengan frekuensi menyusui kurang lebih 8-12 x/hari, durasi menyusui dalam kategori baik $(96,9 \%)$ dengan durasi menyusui kira-kira 10-30 menit dalam setiap kali menyusui dan sebagian besar memiliki pertumbuhan dalam kategori normal. ${ }^{3}$

\section{METODE}

Penelitian ini bersifat Quasi Eksperimental Design dengan pendekatan Non Equevalen Control Group.Lokasi penelitian ini di PMB "E" kota Palangka Raya pada bulan Juli-Oktober 2018. Populasi dalam penelitian ini adalah semua bayi 1-6 bulan di PMB "E" kota Palangka Raya sebanyak 20 orang.

Sampel dalam penelitian ini adalah semua bayi 1-6 bulan di PMB "E" kota Palangka Raya yang memenuhi kriteria inklusi dan eksklusi. Perhitungan besar sampel dalam penelitian ini menggunakan rumus besar sampel untuk eksperimen diperoleh sampel sebesar 20 responden pada setiap kelompok perlakuan maupun kelompok kontrol, untuk mengurangi tingkat kesalahan ditambahkan 10\% sehingga jumlah responden menjadi 22 responden untuk kelompok perlakuan maupun kontrol.

Kriteria Inklusi: Bayi usia 1-6 bulan, bayi sehat (Tidak ada kelainan), bayi lahir cukup bulan, berat badan lahir normal $(\geq$ 2500 gram dan $\leq 4000$ gram), ASI eksklusif, menyusui pada payudara kiri dan kanan, bayi tunggal. Kriteria Eksklusi: Bayi sakit saat pelaksanaan penelitian.

Variabel independen adalah pijat bayi dan variabel dependen adalah frekuensi dan durasi menyusu. Kelompok kontrol dan perlakuan sebelum diberikan perlakuan dilakukan pretest terlebih dahulu. Pada kelompok kontrol diberikan leaflet tentang pijat bayi. Kemudian dilakukan pijat bayi pada kelompok intervensi selama 1 minggu, sebanyak $2 x /$ minggu selama 15 menit. Setelah 1 minggu kemudian dilakukan post test pada kelompok perlakuan dan kontrol. 


\section{HASIL}

Tabel 1. Deskriptif Frekuensi dan Durasi Menyusu pada Bayi

\begin{tabular}{llrrr}
\hline Variabel & Pijat Bayi & Mean & Std. Deviation & $\mathrm{N}$ \\
\hline Frekuensi & Pre Test Pijat & 7,30 & 0,949 & 10 \\
Menyusu & Post Test Pijat & 11,60 & 1,265 & 10 \\
& Pre Test Kontrol & 8,80 & 1,398 & 10 \\
& Post Test Kontrol & 9,20 & 1,932 & 10 \\
& Total & 9,23 & 2.082 & 40 \\
\hline Durasi & Pre Test Pijat & 21,50 & 5,798 & 10 \\
Menyusu & Post Test Pijat & 39,00 & 7,379 & 10 \\
& Pre Test Kontrol & 31,00 & 11,738 & 10 \\
& Post Test Kontrol & 34,00 & 11,972 & 10 \\
& Total & 31,37 & 11,265 & 40 \\
\hline
\end{tabular}

Berdasarkan tabel 1 diketahui bahwa rata-rata frekuensi menyusu pada bayi sebelum dipijat adalah 7,3 kali per hari dengan standar deviasi 0,949 dan rata-rata frekuensi menyusu pada post test adalah 11,6 kali dengan standar deviasi 1,265. Sedangkan pada bayi yang tidak dilakukan pemijatan bahwa rata-rata frekuensi menyusu pada bayi pre test adalah 8,8 kali per hari dengan standar deviasi 1.398 dan rata-rata frekuensi menyusu pada post test adalah 9,23 kali dengan standar deviasi 2,082.
Rata-rata durasi menyusu pada bayi sebelum dipijat adalah 21,50 menit per hari dengan standar deviasi 5,798 dan rata-rata durasi menyusu pada post test adalah 39,00 menit dengan standar deviasi 7,379. Sedangkan pada bayi yang tidak dilakukan pemijatan bahwa rata-rata durasi menyusu pada bayi pre test kontrol adalah 31,00 menit per hari dengan standar deviasi 11,738 dan rata-rata durasi menyusu pada post test adalah 34,00 menit dengan standar deviasi 11,972.

Tabel 2. Analisis Bivariat Frekuensi dan Durasi Menyusu pada Bayi

\begin{tabular}{|c|c|c|c|c|c|c|}
\hline Source & $\begin{array}{l}\text { Dependent } \\
\text { variable }\end{array}$ & $\begin{array}{r}\text { Type III Sum of } \\
\text { Squares } \\
\end{array}$ & df & $\begin{array}{r}\text { Mean } \\
\text { Square }\end{array}$ & $\mathrm{F}$ & Sig. \\
\hline \multirow[t]{2}{*}{ Pijat } & $\begin{array}{l}\text { Frekuensi } \\
\text { Menyusu }\end{array}$ & 95,275 & 3 & 31,758 & 15,513 & 0,000 \\
\hline & $\begin{array}{l}\text { Durasi } \\
\text { Menyusu }\end{array}$ & 1626,875 & 3 & 542,292 & 5,876 & 0,002 \\
\hline
\end{tabular}

Berdasarkan tabel 2 diketahui hasil uji statistik frekuensi menyusu pada tabel 5,2 menunjukkan nilai $p=0,000$ karena $<0,05$ maka $\mathrm{HO}$ ditolak. Hal ini menunjukkan bahwa terdapat pengaruh antara pijat bayi dengan frekuensi menyusu bayi. Hasil uji statistik durasi menyusu diperoleh nilai $p=0,002$, karena hasil uji yang diperoleh $<0.05$ maka $\mathrm{HO}$ ditolak. Hal ini berarti ada pengaruh antara pijat bayi dengan durasi menyusu.

Tabel 3. Analisis Bivariat Frekuensi dan Durasi Menyusu pada Bayi

\begin{tabular}{llrrrrr}
\hline Effect & Value & F & $\begin{array}{l}\text { Hypothesis } \\
\text { df }\end{array}$ & Error df & Sig. \\
\hline Pijat & Pillai's trace & 0,640 & 5,645 & 6,000 & 72,000 & 0,000 \\
& Wilks' Lambda & 0,388 & $7,062^{\mathrm{b}}$ & 6,000 & 70,000 & 0,000 \\
& Hotelling's Trace & 1,505 & 8,531 & 6,000 & 68,000 & 0,000 \\
& $\begin{array}{l}\text { Roy's Largest } \\
\text { Root }\end{array}$ & 1,456 & $17,474^{\mathrm{c}}$ & 3,000 & 36,000 & 0,000 \\
& & & & & \\
\hline
\end{tabular}

Berdasarkan tabel 3 diketahui ada pengaruh yang signifikan dari variabel independen pada semua variabel dependen. Keempat nilai $p$-value menunjukkan $<0,05$.

\section{PEMBAHASAN}

Pada tabel 1 menunjukkan bahwa rata-rata frekuensi menyusu bayi sebelum dilakukan pijat bayi adalah 7.3 kali dan sesudah dilakukan pijat bayi meningkat 
menjadi 11.6 kali. Menurut penelitian Purwani \& Darti (2012) bahwa sebagian besar bayi mendapat frekuensi menyusui dalam kategori baik $(75,0 \%)$ dengan frekuensi menyusui kurang lebih 8-12 x/hari setelah dipijat.

Frekuensi pemberian ASI yang baik yaitu sekitar 8-12x/hari akan meningkatkan berat badan dan mencegah kemungkinan terjadi masalah gangguan pertumbuhan dan perkembangan pada bayi. Frekuensi menyusu pada bayi akan sangat mempengaruhi fisik dan emosional bayi dengan frekuensi menyusu akan meningkatkan kondisi yang tenang kepada bayi dan berat bayi akan bertambah.

Pijat bayi berpengaruh terhadap frekuensi dan durasi menyusu dengan $p$ value 0,03 yang artinya ada pengaruh pijat bayi terhadap frekuensi dan durasi menyusu pada bayi. Penelitian Farida, dkk (2018) menyatakan bahwa ada pengaruh pijat bayi dengan frekuensi menyusu pada bayi dan tidak ada pengaruh pijat bayi dengan durasi menyusu pada bayi. ${ }^{5}$ Hasil penelitian Dieter JNI dkk menunjukkan bahwa terdapat peningkatan berat badan yang lebih pada bayi prematur yang dipijat daripada bayi prematur yang tidak dipijat. $^{6}$

Hasil uji statistik frekuensi menyusu pada table 5.2 nilai $p=0,000$ karena $<0,05$ maka $\mathrm{HO}$ ditolak. Hal ini menunjukkan bahwa terdapat pengaruh antara pijat bayi dengan frekuensi menyusu bayi. Hasil penelitian ini sejalan dengan Fatimah $L$, 2014 yaitu ada Hubungan Frekuensi Pemberian ASI Eksklusif Pada Masa Nifas Dengan Penambahan Berat Badan Bayi Usia 0-6 Minggu. ${ }^{7}$ Pijat bayi menyebabkan bayi menjadi lebih rileks dan dapat beristirahat dengan efektif sehingga ketika bayi terbangun akan membawa energi cukup untuk beraktivitas. Bayi menjadi cepat lapar saat beraktivitas dengan optimal sehingga nafsu makannya meningkat. Peningkatan nafsu makan ini juga ditambah dengan peningkatan aktivitas nervus vagus (sistem sarat otak yang bekerja untuk daerah leher ke bawah sampai dadadan rongga perut) dalam menggerakkan sel peristaltik untuk mendorong makanan ke saluran pencernaan, sehingga bayi lebih cepat lapar atau ingin makan karena pencernaannya semakin lancar. ${ }^{7}$

Pada Tabel 1 Diketahui bahwa ratarata durasi menyusu pada bayi sebelum dipijat adalah 21.50 menit per hari dan ratarata durasi menyusu pada post test adalah 39.00 menit. Menurut penelitian Purwani \&
Darti (2012) bahwa sebagian besar durasi menyusu bayi dalam kategori baik (96,9\%) dengan durasi menyusu kira-kira 10-30 menit dalam setiap kali menyusui dan sebagian besar memiliki pertumbuhan dalam kategori normal. $^{3}$

Berdasarkan hasil uji statistik pada tabel 2.1 durasi menyusu diperoleh nilai $p=0.002$, karena hasil uji yang diperoleh $<0.05$ maka $\mathrm{HO}$ ditolak. Hal ini berarti ada pengaruh antara pijat bayi dengan durasi menyusu. Hasil penelitian yang sama menurut Fitriahadi tahun 2016, hasil uji Chi Square menunjukkan bahwa pengaruh pijat bayi terhadap frekuensi dan durasi menyusu pada bayi didapatkan hasil $p$ value 0,03 (karena $p$ value $>0,05$ ) maka Ho ditolak dan Ha diterima yang artinya ada pengaruh pijat bayi terhadap frekuensi dan durasi menyusu pada bayi. ${ }^{8}$

Hasil penelitian ini sejalan dengan Kundarti FI tahun 2011 bahwa ada pengaruh pemijatan terhadap kenaikan berat badan dan lama tidur bayi usia 1 sampai 3 bulan. ${ }^{9}$ Pijat bayi menyebabkan bayi menjadi lebih rileks dan dapat beristirahat dengan efektif sehingga ketika bayi terbangun akan membawa energi cukup untuk beraktivitas. Bayi menjadi cepat lapar saat beraktivitas dengan optimal sehingga nafsu makannya meningkat. Peningkatan nafsu makan ini juga ditambah dengan peningkatan aktivitas nervus vagus (sistem sarat otak yang bekerja untuk daerah leher ke bawah sampai dengan rongga perut) dalam menggerakkan sel peristaltik untuk mendorong makanan ke saluran pencernaan, sehingga bayi lebih cepat lapar atau ingin makan karena pencernaannya semakin lancar.

\section{KESIMPULAN DAN SARAN}

Pijat bayi mempengaruhi Frekuensi menyusu dan durasi menyusu pada bayi. Saran bagi petugas kesehatan agar menjadikan terapi pijat bayi sebagai terapi alternatif dalam mendukung ASI eksklusif. Bagi masyarakat khususnya ibu menyusui agar rutin untuk melakukan pijat bayi setiap hari oleh orang tua bayi atau minimal 2 kali seminggu. Kebutuhan nutrisi bayi terpenuhi karena durasi dan frekuensi menyusu meningkat. Bagi peneliti selanjutnya agar mengembangkan penelitian dengan menggunakan variabel lain seperti produksi ASI yang belum diteliti terkait dengan pijat bayi. 


\section{UCAPAN TERIMAKASIH}

Peneliti berterima kasih kepada tempat penelitian Praktik Bidan Mandiri milik bidan " $E$ " yang telah memfasilitasi peneliti selama proses pengambilan data ini berlangsung.

\section{DAFTAR PUSTAKA}

1. Roesli U. Pedoman pijat bayi edisi revisi. Jakarta. PT.Trubus Agriwidy; 2010.

2. Falikhah A \& Hidayat A. Pengaruh pijat bayi terhadap frekuensi menyusui pada bayi 03 bulan di BPS Dini Melani Condong Catur Sleman Yogyakarta. Unisa Digital Library; 2011.

3. Purwani \& Darti. Hubungan Antara Frekuensi, Durasi Menyusui dengan Berat Badan Bayi di Poliklinik Bersalin Mariani Medan. Jurnal Keperawatan Klinis Vol 4 No $1 ; 2012$.

4. Fitrihadi. Pengaruh pijat bayi terhadap frekuensi dan durasi menyusu pada bayi. Jurnal Kesehatan Masyarakat Vol.10 No.2 September; 2016.
5. Farida Y, Mardianti, Komalasari L. Pengaruh pijat bayi terhadap peningkatan frekuensi dan durasi menyusu pada bayi usia 1-3 bulan. Jurnal Kebidanan Vol.7 No. $1 ; 2018$.

6. Dieter JNI, Field T, Hernandez M, Eugene, Redzepi M. Stable preterm infant gain more weight and sleep less after five days of massage therapy. Journal of pediatric psychology vol 28, no 6; 2014.

7. Fatimah L. Hubungan Frekuensi Pemberian ASI Eksklusif Pada Masa Nifas Dengan Penambahan Berat Badan Bayi Usia 0-6 Minggu. Jurnal Eduhealth Vol 4 No 1 April ; 2014.

8. Fitriahadi Enny. Pengaruh pijat bayi terhadap peningkatan frekuensi dan durasi menyusu pada bayi. Jurnal kesehatan Masyarakat. Vol. 10 No. 2; 2016.

9. Kundarti FI. Pengaruh pemijatan terhadap kenaikan berat badan dan lama tidur bayi usia 1 sampai 3 bulan. Jurnal penelitian kesehatan suara forikes vol II; 2011 